\title{
Low bone mineral density in small for gestational age infants: correlation with cord blood zinc concentrations
}

\author{
F Chunga Vega, M J Gómez de Tejada, J González Hachero, R Pérez Cano, C Coronel \\ Rodriguez
}

\begin{abstract}
Twenty eight term small for gestational age (SGA) infants and 18 term appropriate for gestational age (AGA) infants were studied prospectively to assess bone mineral density and cord serum zinc concentrations. Growth and nutritional status were evaluated, and bone mineral density was measured by dual energy $x$ ray densitometry of the lumbar spine. Cord serum zinc, parathyroid hormone, osteocalcin, vitamin $D$ metabolite and mineral concentrations were measured.

Growth, nutritional status, and bone mineral density (mean (SD) $0.223(0.032)$ vs $0.277(0.032) \mathrm{g}$ hydroxyapatite $\left./ \mathrm{cm}^{2}\right)$ were significantly low in SGA infants. Bone mineral density was linearly related to growth and nutritional measures. Cord serum zinc concentrations were in the normal range and similar in both groups (mean (SD) 13.86 (3.0) vs 13.43 (2.1) $\mu \mathrm{mol} / \mathrm{I})$.

It is suggested that SGA infants may not be zinc deficient. Low bone mineral density could be caused by growth and nutritional status deficiencies, the mechanisms for which could be those that reduce nutrient substrate supply to the fetus. (Arch Dis Child 1996;75:F126-F129)
\end{abstract}

Keywords: zinc deficiency, growth, bone density, SGA infants.

Previous studies have reported low bone mineral density in small for gestational age infants (SGA) compared with appropriate for gestational age (AGA) infants, when bone mineral content was measured by single photon (125 I) absorptometry (SPA) at the distal third of the radius, ${ }^{1}$ or at the mid humerus, ${ }^{2}$ or when total body bone mineral was determined by double photon absorptiometry (153 densitometry). ${ }^{3}$ In addition to low bone mineral content, low cord serum 1,25dihydroxyvitamin $\mathrm{D}(1,25-(\mathrm{OH}) 2 \mathrm{D})$ and osteocalcin concentrations have been found, as evidence of decreased bone formation. ${ }^{1}$ The reason for low bone mineral density in SGA infants is not clear.

Cord serum zinc concentrations may be low in SGA infants and may correlate with birthweight. ${ }^{45}$ Growth retardation is an important change associated with zinc deficiency in both humans and animals. ${ }^{46}$ Experimental studies of zinc deprivation on pregnant rhesus monkeys showed significant retarded bone ossification and characteristic rachitic changes in the fetus; these may result from alterations in the vitamin D system. ${ }^{7}$ Serum $1,25-(\mathrm{OH}) 2$ D concentrations were decreased in zincphosphorus deficient rats, consistent with the trace element as a metallo-enzyme that would modulate renal $1 \alpha$ hydroxylase activity. ${ }^{8} \mathrm{We}$ wanted to test the following hypothesis: cord serum zinc concentrations would be low in intrauterine growth retarded infants; low cord zinc concentrations would result in growth deficiency, low cord serum 1,25-(OH)2 D concentrations, and low bone mineral density in SGA infants.

\section{Methods}

We studied 46 term singleton newborns (born at 37 to 41 weeks of gestation). They were divided into two groups: 28 SGA infants and 18 AGA infants. Gestational age was calculated from the first day of the last menstrual period and was verified (within two weeks of that calculated date) by clinical assessment of the infant at birth using the Ballard score method. ${ }^{9}$ Infants were classified as SGA if their birthweight was below the 10 th percentile on the intrauterine growth chart of Lubchenco et $a l .{ }^{10}$ Eight infants in the SGA group and 10 in the AGA group were boys; all newborns were Spanish. Gender and race differences in bone mineral density have not been found at birth. ${ }^{1}$ All the infants had been born at the University Hospital Virgen Macarena, Seville, Spain, between October 1992 and October 1993.

Term healthy infants were recruited in the delivery room; all had been born after uncomplicated pregnancies and deliveries. We excluded infants with clinical conditions known to affect calcium metabolism, such as diabetes or parathyroid, bone, or gastrointestinal diseases, or whose mothers had any of the above. None of the SGA infants had clinical evidence of chromosomal abnormalities, or intrauterine infection, or malformations.

The study was approved by the institutional review board of the University Hospital Virgen Macarena and parental informed consent obtained.

Birthweight and crown-heel length, head circumference, mid arm circumference, triceps and subscapular skinfolds, and body surface area (between 48 and 72 hours of life) were measured in duplicate by the same investigator (FCV). All these measurements were made using standard techniques. For weight we used 
Table 1 Growth and nutritional status measures, and bone mineral density values

\begin{tabular}{|c|c|c|c|}
\hline & $S G A(n=28)$ & $A G A(n=18)$ & $P$ value \\
\hline \multicolumn{4}{|l|}{ Body weight (g) } \\
\hline Mean (SD) & $2223.7(206.6)$ & $3453.0(351.9)$ & $<0.001$ \\
\hline Range & $(1680-2500)$ & $(2810-4200)$ & \\
\hline \multicolumn{4}{|c|}{ Crown-heel length $(\mathrm{cm})$} \\
\hline Mean (SD) & $45.71(1.42)$ & $50.0(1.68)$ & $<0.001$ \\
\hline Range & $(42.5-49.5)$ & $(47.0-54.0)$ & \\
\hline \multicolumn{4}{|c|}{ Head circumference $(\mathrm{cm})$} \\
\hline Mean (SD) & $32.50(0.79)$ & $34.96(0.99)$ & $<0.001$ \\
\hline Range & $(31.3-34.3)$ & $(33.5-37.0)$ & \\
\hline \multicolumn{4}{|c|}{ Body surface area $\left(\mathrm{m}^{2}\right)$} \\
\hline Mean (SD) & $0.1589(0.009)$ & $0.2058(0.013)$ & $<0.001$ \\
\hline Range & $(0.135-0.17)$ & $(0.180-0.23)$ & \\
\hline \multicolumn{4}{|c|}{ Mid-arm circumference $(\mathrm{cm})$} \\
\hline Mean (SD) & $8.22(0.62)$ & $10.47(0.90)$ & $<0.001$ \\
\hline Range & $(6.5-9.2)$ & $(8.0-11.5)$ & \\
\hline \multicolumn{4}{|l|}{ MAC:HC } \\
\hline Mean (SD) & $0.253(0.021)$ & $0.298(0.024)$ & $<0.001$ \\
\hline Range & $(0.203-0.287)$ & $(0.238-0.328)$ & \\
\hline \multicolumn{4}{|c|}{$\mathrm{BMD}\left(\mathrm{g} \mathrm{HAP} / \mathrm{cm}^{2}\right)$} \\
\hline Mean (SD) & $0.223(0.032)$ & $0.277(0.032)$ & $<0.001$ \\
\hline Range & $(0.145-0.279)$ & $(0.211-0.332)$ & \\
\hline
\end{tabular}

$\mathrm{BMD}=$ bone mineral density; $\mathrm{SGA}=$ small for gestational age infants; $\mathrm{AGA}=$ appropriate for gestational age infants; MAC:HC = mid-arm circumference ratio.

Student's $t$ test was used to determine differences in measurements between groups.

a Seca electric scale model 727; a metal board for crown-heel length measurement; a nonstretchable cloth measuring tape for head and mid arm circumference; and a single set of GMC skinfold callipers for skinfold thickness. Body surface area was calculated using a Dubois nomogram. Mid arm circumference and mid arm circumference:head circumference ratio (MAC:HC) measurements were used as indices of nutritional status. ${ }^{11}$

Bone mineral density and content were determined on the lumbar spine (L2-L4) within three to five days after birth by dual energy $x$ ray absorptometry ( Hologic QDR 1000 densitometer ) (DEXA), which uses an $x$ ray tube as the radiation source. The system scans the lumbar spine rectilinearly. The $x$ ray tube pulses alternately at 70 and $140 \mathrm{kV}$, and the instrument has an internal reference system that compensates for drift in measurements. The radiation dose to the child is less than $5 \mathrm{mRem}$ which is about one tenth of the exposure from a standard chest $x$ ray. Previous studies have validated this technique (L1-L5 and L1-L4). ${ }^{1213}$ During measurement, the infants were lying prone, with their legs in spontaneous semiflexion. Some were sedated (chloral hydrate $10 \mathrm{mg} / \mathrm{kg}$ ). The scanning time for the region of interest ranged from 2 to 3 minutes, depending on the child's size. In our hospital the coefficient of variation in adults is $1.4 \%$ and $3.5 \%$ in neonates $(n=20$, three determinations for each one). Dual energy $x$ ray energy expresses bone mineral density in $\mathbf{g}$

Table 2 Correlation between lumbar spine BMD and $B M C$ with growth and nutritional status measures in 46 $(28 S G A+18 A G A)$ infants

\begin{tabular}{llllll}
\hline & \multicolumn{2}{l}{$B M D$} & & & \multicolumn{2}{l}{$B M C$} \\
\cline { 2 - 3 } \cline { 6 - 7 } & $R$ & $P=$ & & $R$ & $P=$ \\
\hline Body weight & 0.73 & 0.000 & & 0.80 & 0.000 \\
Crown-heel length & 0.62 & 0.000 & & 0.81 & 0.000 \\
Head circumference & 0.60 & 0.000 & & 0.73 & 0.000 \\
Mid-arm circumference & 0.58 & 0.000 & & 0.61 & 0.000 \\
MAC:HC ratio & 0.48 & 0.001 & & 0.47 & 0.001 \\
Body surface area & 0.72 & 0.000 & & 0.83 & 0.000 \\
\hline BMD: bone mineral density. & & & &
\end{tabular}

BMC: bone mineral content. (hydroxyapatite) per $\mathrm{cm}^{2}$ and bone mineral content in $\mathbf{g}$ hydroxyapatite. All images were processed by the same investigator (MJGT). Lumbar spine DEXA measurements have advantages over traditional SPA, because they include the metabolically active trabecular bone. ${ }^{12}{ }^{13}$ Cord blood was drawn by venepuncture from the placental side of the clamped umbilical vein with a stainless needle and a plastic syringe, deposited in zinc free tubes and immediately centrifuged at $4000 \mathrm{rpm}$; the separated serum was kept in zinc free tubes at $-20^{\circ} \mathrm{C}$ until biochemical determinations were carried out. Cord serum concentrations of zinc, intact parathyroid hormone (PTH), 25-OHD, 1,25-(OH)2D, osteocalcin, total calcium, and inorganic phosphorus were determined using established methods.

Zinc was measured by atomic absorption spectrometry (model 1100, Perkin-Elmer Corporation, Norwalk, Connecticut, USA). The normal adult range is 10.7 to $18.5 \mu \mathrm{mol} / 1$ (70$120 \mu \mathrm{g} / \mathrm{dl}$ ); intra-assay coefficient of variation is $3.5 \%$. Serum intact PTH was measured by immunoradiometric assay using a commercial kit from INCSTAR Corporation, Stillwater, Minnesota, USA. Serum 25-OHD and serum $1,25-(\mathrm{OH}) 2 \mathrm{D}$ were measured using radioimmunoassay and a non-competitive protein binding assay, respectively (INCSTAR). Serum osteocalcin was determined by a solid phase sandwich immunoradiometric assay (CIS Bio International, Gif surYvette, France). Serum total calcium was determined using the O-Cresolphthalein method ( BM/Hitachi 747/ 737; Boehringer Mannheim Laboratories, Germany ). The adult normal range is 2.02 to $2.59 \mathrm{mmol} / 1$ (8.10-10.4 mg/dl). Serum inorganic phosphorus was measured using the molybdate reaction method ( BM/Hitachi 747/ 737; Boehringer Mannhein Laboratories). The normal adult range is 0.87 to $1.45 \mathrm{mmol} / \mathrm{l}$ (2.7-4.5 mg/dl ).

Student's $t$ test was used to determine differences in measurements between the SGA and AGA groups. The Pearson correlation coefficient was applied. $P$ values for intact PTH, 25-OHD, 1,25-(OH)2 D and osteocalcin were determined using the Mann-Whitney nonparametric test. A $\mathrm{P}$ value of $<0.01$ was regarded as significant.

\section{Results}

Gestational age and birthweight were mean (SD)38.96 (1.29) weeks and 2223.75 (206.56) $\mathrm{g}$ for SGA infants and $39.89(0.9)$ weeks; 3453.06 (351) g for AGA infants, respectively.

Weight, length, head circumference, surface area, mid arm circumference, and MAC:HC ratio at birth were significantly lower in SGA than in AGA infants $(P<0.001)$ (table 1 ).

The mean value of lumbar spine bone mineral density was significantly lower in SGA infants than in AGA infants $(P<0.001)$; the mean value of bone mineral content was also lower in SGA than in AGA infants (data not shown) (table 1). The bone mineral density and bone mineral content of all patients corre- 
Table 3 Cord serum minerals, intact parathyroid hormone, vitamin $D$ metabolites, and osteocalcin in $S G A$ vs $A G A$ infants

\begin{tabular}{|c|c|c|c|}
\hline & $S G A$ infants & $A G A$ infants & Pvalue \\
\hline $\begin{array}{l}\text { Zinc: } \\
\quad(\mu \mathrm{mol} / \mathrm{l}) \\
(\mu \mathrm{g} / \mathrm{dl})\end{array}$ & $\begin{array}{l}13.86(3.00)(n=22) \\
90.61(19.64)\end{array}$ & $\begin{array}{l}13.42(2.18)(n=16) \\
87.77(14.23)\end{array}$ & 0.631 \\
\hline $\begin{array}{l}\text { Calcium: } \\
\text { (mmol/l) } \\
(\mathrm{mg} / \mathrm{dl})\end{array}$ & $\begin{array}{r}2.55(0.23)(\mathrm{n}=27) \\
10.23(0.95)\end{array}$ & $\begin{array}{l}2.43(0.21)(n=14) \\
9.75(0.85)\end{array}$ & 0.120 \\
\hline $\begin{array}{l}\text { Phosphorus: } \\
\text { (mmol/) } \\
\text { (mg/dl) }\end{array}$ & $\begin{array}{l}2.06(0.44(n=22) \\
6.40(1.38)\end{array}$ & $\begin{array}{l}2.49(0.56)(n=11) \\
7.72(1.73)\end{array}$ & 0.024 \\
\hline $\begin{array}{l}\text { Intact PTH: } \\
\text { (pg/ml) } \\
\text { Range }\end{array}$ & $\begin{array}{c}13.71(26.1)(n=14) \\
(1.19-97.43)\end{array}$ & 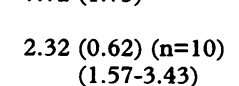 & 0.061 \\
\hline $\begin{array}{c}\text { 25-(OH) D: } \\
\text { (ng/ml) } \\
\text { Range }\end{array}$ & $\begin{array}{c}16.92(10.87(n=14) \\
(4.0-38.0)\end{array}$ & $\begin{array}{c}11.0(8.45)(n=10) \\
(4.0-29.0)\end{array}$ & 0.104 \\
\hline $\begin{array}{c}\text { 1,25-(OH)2 D: } \\
\text { (pg/ml) } \\
\text { Range }\end{array}$ & $\begin{array}{c}12.37(8.69)(n=14) \\
(3.6-35.6)\end{array}$ & $\begin{array}{c}13.69(9.02)(n=10) \\
(4.8-32.1)\end{array}$ & 0.725 \\
\hline $\begin{array}{l}\text { Osteocalcin: } \\
\text { (ng/ml) } \\
\text { Range }\end{array}$ & $\begin{array}{r}34.74(35.1)(n=14) \\
(3.05-136.42)\end{array}$ & $\begin{aligned} & 44.67(27.6)(n=10) \\
&(17.09-88.94)\end{aligned}$ & 0.143 \\
\hline
\end{tabular}

$P$ values for minerals were determined by Student's $t$ test; and for intact PTH, vitamin D metabolite, and osteocalcin, by Mann Whitney non-parametric test.

lated positively with weight, length, head circumference, MAC, MAC:HC ratio, and surface area at birth $(P<0.001)$. Bone mineral content and density were proportional to weight, length, head circumference, MAC, MAC:HC ratio, and surface area. The strongest correlation was with weight, length, head circumference and surface area (table 2).

Cord serum zinc concentrations were within the normal ranges and differences were not found between SGA and AGA infants (table 3 ); zinc concentrations did not correlate with weight, length, bone mineral density, or serum $1,25-(\mathrm{OH}) 2 \mathrm{D}$.

Cord serum PTH, intact 25-OHD, 1,25$(\mathrm{OH}) 2 \mathrm{D}$, osteocalcin, total calcium and inorganic phosphorus concentrations were not significantly different between the two groups of infants (table 3). This lack of difference in cord serum concentrations cannot be stated with confidence, because our sample was rather small.

\section{Discussion}

Defining SGA infants by weight below the tenth percentile, ${ }^{10}$ we found, as expected, that growth and nutritional measures (table 1) were lower in SGA than in AGA infants. ${ }^{11}{ }^{14}$ The degree of this reduction presumably depends on the extent of the intrauterine insult. In a sequence from "mild" to "severe" this would affect length, height, and head circumference, respectively ${ }^{1}$ : these were significantly low in SGA infants $(P<0.001)$, suggesting possible moderate to severe intrauterine growth retardation. We used Lubchenco et al's intrauterine growth chart, ${ }^{10}$ because it includes an heterogenous population and we do not have any locally applicable chart.

Lumbar spine bone mineral density (DEXA L2-L4) was significantly lower in SGA than in AGA infants, confirming previous results (table 1 ) when bone mineral content was measured by SPA (radius, humerus), ${ }^{12}$ or doublephoton densitometry in SGA infants (total body bone mineral content). ${ }^{3}$
Our hypothesis was that serum zinc concentrations would be low in SGA infants, and that this would negatively affect growth, 1,25$(\mathrm{OH}) 2 \mathrm{D}$ production, and bone metabolism; this hypothesis was not confirmed. Similar to Bro et al, ${ }^{15}$ we found normal mean cord serum zinc concentrations in SGA and AGA infants (table 3); no correlation with growth and nutritional measures was found. These data are different from those of Jeswani et al, ${ }^{5}$ who reported mean cord serum zinc concentrations significantly lower in SGA than in AGA term infants (111.8 (9.2) $\mu \mathrm{g} / \mathrm{dl}$ vs 128.88 (14.37) $\mu \mathrm{g} / \mathrm{dl})$, although the values were in the normal range and correlated positively with weight. ${ }^{45}$ Our results suggest that SGA infants may not be zinc deficient even though our newborns seemed to be moderately to severely growth retarded. Hypozincaemia is found in very severe zinc deficiency in animals and only rarely in humans. ${ }^{6}$

The bone mineral density and content of all the infants were linearly related to weight, length, head circumference, MAC, MAC:HC ratio and surface area; the best correlation was with weight, length, head circumference and surface area (table 2), similar to bone mineral content measured by SPA on the distal third of the left radius, and total bone mineral content by DEXA in healthy term newborns. ${ }^{16}$ Salle et al (DEXA L1-LA) also found a positive correlation between bone mineral density and content with weight, length, head circumference, and surface area in AGA neonates, even though the correlation between bone mineral density and gestational age or length was weaker. ${ }^{13}$

The correlation between bone mineral density and fetal growth and nutritional measures suggests that the causes and mechanisms for reduced bone mineral density in SGA infants may be similar to those that usually reduce intrauterine weight. ${ }^{1}$ From haemodynamic studies and other methods, we know that the reduction of uteroplacental blood flow is a primary factor $(40 \%)$ in intrauterine growth retardation. ${ }^{17} 18$ Cord serum amino acid concentrations are low in SGA fetuses; amino acids are used by the fetus and placenta for both protein synthesis and energy production. ${ }^{19}$ Theoretically, bone mineralisation may be affected because of deficiency of bone protein collagen synthesis. Low bone mineral density in SGA infants may also be due to imbalance or transplacental deficiency supply of minerals that participate in bone formation. ${ }^{1}$ Experimental reduction of placental blood supply in rats causes intrauterine growth retardation; the calcium transport is reduced relative to the reduction in body size. ${ }^{20}$ Alterations in phosphate delivery to the bone in SGA infants may also affect bone formation rates and osteocalcin metabolism; the administration of phosphates in adults and preterm infants influences the process of bone remodelling. ${ }^{21}$ this process is associated with bone enlargement, body growth, and muscular mass.

Our data showed low bone mineral density in SGA infants, but not low cord serum 
1,25- $(\mathrm{OH}) 2 \mathrm{D}$ or osteocalcin concentrations (table 3) as did Namgung et al, ${ }^{1}$ but it has to be borne in mind that our sample was rather small.

We speculate that low bone mineral density in SGA infants is the result of growth and nutritional deficiencies. The causes and mechanisms are those that produce a reduction in nutritional substrate supply to the fetus, hence bone mineral content correlates well with growth and nutritional status.

We conclude that bone mineral density is lower in SGA than in AGA infants. The low density correlates positively with reduced fetal growth and nutritional status, which is consistent with a similar aetiology and mechanisms for both outcomes. There were no differences in cord serum zinc, intact PTH, vitamin D metabolite, mineral and osteocalcin values between groups.

We thank Professor Reginald C Tsang (Cincinnati, Ohio) for his helpful suggestions. We also thank Drs José Molina and Rosa Moruno for performing serum biochemical measurements.

Moruno for performing serum biochemical measurements.
This study was supported by the Heinz Koch Foundation, This study was sup

1 Namgung R, Tsang TC, Specker BL, Sierra RI, Ho ML. Reduced serum osteocalcin and 1,25- dihydroxyvitamin D Reduced serum osteocalcin and 1,25- dihydroxyvitamin $D$
concentrations and bone low mineral content in small for gestational age infants: Evidence of decreased bone formation rate. $\mathcal{F}$ Pediatr 1993;122:269-75.

2 Pohlandt F, Mathers N. Bone mineral content of appropriate and light for gestational age preterm and term newborn infants. Acta Paedriatr Scand 1989;78:835-9.

3 Petersen S, Gotfredsen A, Knudsen FU. Total body bone mineral in light-for-gestational age infants and appropriate-for- gestational age infants. Acta Paediatr Scand 1989;78:347-50.

4 Malhotra A, Fairweather-Tait SJ, Wharton PA, et al. Placental zinc in normal and intra-uterine growth-retarded pregtal zinc in normal and intra-uterine

5 Jeswani RM, Vani SN. A study of serum zinc levels in cord blood of neonates and their mothers. Indian $\mathcal{F}$ Pediatr 1991;58:683-6.
6 Chesters JK. Metabolism and biochemistry of zinc. In: Prasad AS, ed. Clinical biochemical and nutritional aspects of trace elements. New York: Alan R Liss, 1982:221-38.

7 Leek JC, Vogler JB, Gershwin ME, et al. Studies of marginal zinc deprivation in thesus monkeys. V. Fetal and infant skeletal effects. Am $\mathcal{f}$ Clin Nutr 1984;40:1203-12.

$8 \mathrm{Kimmel} \mathrm{PL}$, Watkins DW, Slatopolsky E, et al. 1,25 (OH)2D response to combined zinc and phosphorus depletion rats. Am f Physiol 1990;259:319-26.

9 Ballard J, Kazmaier-Novak K, Driver M. Simplified score for assessment of fetal maturation of newly born infants. $\mathcal{F}$ Pediatr 1979;95:769-74.

10 Lubchenco L, Hansman C, Boyd E. Intrauterine growth in weight, length and head circumference as estimated from weight, length and head circumference as estimated from live births at gesta

11 Sasanow S, Georgieff M, Pereira G. Mid-arm circumference and mid-arm circumference/head circumference ratios: standard curves for anthropometric assessment of neonatal nutritional status. $\mathcal{F}$ Pediatr 1986;109:311-15.

12 Braillon PM, Salle BL, Brunet J, Glorieux FH, Delmas PD, Meunier PJ. Dual energy X-ray absorptiometry measurement of bone mineral content in newborns: validation of the technique. Pediatr Res 1992;32:77-80.

13 Salle BL, Braillon PM, Glorieux FH, Brunet J, Cavero E, Meunier PJ. Lumbar bone mineral content measured by dual energy $X$-ray absorptiometry in newborns and infants. Acta Paediatr 1992;81:953-8.

14 Palacios J, Rodriguez S, Rodriguez GI. Intrauterine long bone growth in small for gestational age infants. Eur $\mathscr{f}$ Pediatr 1992;151:304-7.

15 Bro S, Berendtsen H, Norgaard J, Host A, Jorgensen PJ. Serum zinc and copper concentrations in maternal and in Serum zinc and copper concentrations in maternal and in pregnancy. Scand f Clin Lab Invest 1988;48:805-11.

16 Venkataraman PS, Ahluwalia BW. Total bone mineral content and body composition by $\mathrm{X}$-ray densitometry in newborns. Pediatrics 1992;90:767-70.

17 Nisell H, Lunell N-O, Linde B. Maternal hemodynamics and impaired fetal growth in pregnancy-induced hypertension. Obstet Gynecol 1988;71:163-6.

18 Trudinger BJ, Cook CM. Doppler umbilical and uterine waveforms in severe pregnancy hypertension. Br 7 Obstet waveforms in severe pregn

19 Cetin I, Corbetta C, Sereni LP, et al. Umbilical amino acids concentrations in normal and growth retarded fetuses sampled in utero by cordocentesis. Am $\mathcal{F}$ Obstet Gynecol 1990;162:253-1.

20 Mughal MZ, Ross R, Tsang RC. Clearance of calcium across in situ perfused placentas of intrauterine growthretarded rat fetuses. Pediatr Res 1989;25:420-2.

21 Prestridge LI, Schandler RJ, Shulman RJ, Burns PA, Laine LL. Effect of parenteral calcium and phosphorus therapy on mineral retention and bone mineral content in very low birth weight infants. $\mathcal{f}$ Pediatr 1993;122:761-8. 